\title{
Can Digital Signage Help Consumers Eat Healthier?
}

\author{
Anicia Peters ${ }^{1}$ and Brian Mennecke ${ }^{2}$ \\ ${ }^{1}$ Human Computer Interaction Program, Virtual Reality Applications Center, 1620 Howe Hall \\ ${ }^{2}$ Supply Chain and Information Systems, College of Business, 3313 Gerdin, \\ Iowa State University, Ames, Iowa, 50011, USA \\ anpeters@iastate.edu, mennecke@iastate.edu
}

\begin{abstract}
Digital signage has become prevalent in public spaces, but consumers are faced with many choices from various displays with the result that consumers often ignore important information. To "recover" customer attention, various retailers have recently begun to deploy dynamic digital menu boards, which are plasma screens that combine the power of video with multimedia content. We examine the effect of these boards on healthy eating, a topic that has been on the national agenda for some time as Americans struggle with obesity. The introduction of a specialized form of dynamic digital menu boards in fast food restaurants has the potential to increase unhealthy eating if retailers were to use them to "upsell" consumers to higher margin but less healthy menu items. By the same token, these boards could also be used to influence consumers to make healthier food choices resulting in benefits to the consumer and society.
\end{abstract}

Keywords: digital dynamic menu boards, digital signage, healthy eating, consumer decision-making, vividness.

\section{Introduction}

Our research question focuses on the effects of video and static image food ads in dynamic digital menu boards on consumer decision-making processes and, specifically, on healthy food choices. Digital signage is a type of public computergenerated plasma display screen that presents multimedia content [3].

Due to the prevalence of these displays in public spaces, the quest for more attention-grabbing features, and significant advances in technology has enabled digital signage venders to offer signage with advanced functionality and eye-catching content. Recently, many fast-food restaurants have begun to replace traditional menu boards with dynamic digital menu boards that are capable of displaying video and live news feeds [13]. A retailer can take advantage of one of digital signage's prominent features; that is, the potential to immediately update content at the source outlet or from a centralized location $[3,13]$.

As an illustration of the importance of these emerging technologies, fast food restaurants such as Wendy's have already begun to deploy and test video menu boards [13]. Wendy's uses these technologies to embed video ads with the goal of "grabbing" the attention of the user and redirecting their focus to particular menu items. 
Further, because the dynamic digital menu board is used to replace the static menu the digital boards are the only source of information about product offerings and, therefore, the consumer will by necessity attend to the content of the display when placing orders. Of course, while the primary content of these menu boards will display product features such as price and quantity, they can be used to display other product features such as nutritional information or to enhance the appearance of product offerings. As digital signage becomes more common, it will be more likely that consumers will filter out important contents such as nutritional information or other health related messages; therefore, understanding the factors that influence consumer perceptions about these displays and the display content is important.

\section{Information Overload and Vividness}

Traditional static menus are commonly "cluttered" with information, which implies that dynamic digital menu boards containing video and moving images might foster additional information overload. Researchers have observed a "display blindness" that occurs as part of a coping strategy to deal with situations where displays offer abundant and cluttered information [7,9]. In these circumstances, consumers ignore digital signage because it is often irrelevant to their task or is perceived as a distraction $[3,9]$.

Dynamic digital menu boards and the associated "clutteredness" might also contribute to information overload and negatively affect decision-making. Information overload occurs when an individual perceives that too much information needs to be processed within a given time and, as a result, the individual feels overwhelmed $[1,5,8]$.

Research suggests that video content in digital signage stands out as an attention grabber due to its liveliness and video has the ability to overcome the "display blindness" effect [7, 9]. In our studies, we hypothesize that the vividness of video will "grab" the consumer's attention and influence decision-making. We use the definition of vividness offered by Nisbett and Ross that “...information may be described as vivid, that is, as likely to attract and hold our attention and to excite the imagination to the extent that it is a) emotionally interesting, b) concrete and imagery provoking, and c) approximate in a sensory, temporal, or spatial way" [10]. We will design our manipulations with static images, text, and video in one condition to examine Taylor and Thompson's thesis that suggests that a vividness effect has not been conclusively demonstrated as most studies manipulated vivid and non-vivid information separately and used a between participants contrast [12].

\section{Consumer Decision-Making and Healthy Eating}

In order to investigate whether consumers' decision-making can be influenced by the vividness of video ads and subsequently whether consumers can be influenced to make healthier food choices, we need to understand consumer decision-making processes. We used the basic 5-step consumer decision-making model of Engel et al. [4] due its simplicity. The steps are: a) motivation and need recognition, b) search, 
c) alternatives search, d) choice and e) outcomes. Nevertheless, we also realize that many moderating factors are present that may cause consumers to vary the decision rules they use and the process they undertake to make a decision [2, 6]. In our research model we will consider moderating factors such as the characteristics of the consumer, the relevance of the ad content to the task, the preference of the consumer, information overload conditions, and information display formats.

At first, our supposition was that video displays would primarily function as a recommender system whereby the ads influence cognitive focus and influence decision-making strategies. Subsequently, we recognized that these technologies had the potential to positively influence choices made regarding healthy eating. For example, industry reports suggest that venders earn positive ROI from dynamic digital menu boards because consumers often preferentially choose offerings in video ads even when prices are higher [13]. As a result, video displays can potentially "guide" consumers to make healthy food choices when the display content includes healthy alternatives.

Our study design takes into consideration that healthy food choices are subjective; for example, consumers might automatically assume that salads are healthy, but do not consider nutritional information for salad dressings. Because healthy food choices can be depicted as appetizing in video ads, we hypothesize that the vividness of moving imagery in the video ads will attract attention and lead consumers to evaluate their decisions in the context of health considerations. Further, if these displays include nutritional information we might be able to encourage consumers to focus on these criteria during the information search stage. Consumers might even truncate the information search stage for nutritional information when faced with "healthy" food options that are displayed using attractive and "eye-catching" imagery.

\section{Hypotheses}

We have developed a research model from which we derive hypotheses as follows [11]:

- H1: When a consumer is faced with too much information, a video ad in a dynamic menu board with greater vividness would be more likely to draw attention regardless of whether it features healthy or unhealthy options.

- H1a: A video with more motion, bright colors, realistic representations, sharp images, and distinctive and unique content will be more likely to attract the attention of the consumer.

- H2: The vividness of video will lead to the evaluation of fewer alternatives regardless of healthy choices.

- H2a: The vividness of video will reduce the consumer's perception of decision complexity.

- H2b: The vividness of video will lead to high levels of involvement and reduce perceptions of decision complexity by allocating resources necessary to evaluate the stimuli fully and completely.

- H3: Under conditions of information overload, the video will become a reference heuristic regardless of whether the content includes healthy information. 
- H3a: The availability bias of the video will increase the likelihood of the featured item being purchased regardless of whether it was a healthy or unhealthy option.

- H3b: The persuasiveness of the vividness effect will increase the likelihood of the featured item being purchased regardless of whether it was a healthy or unhealthy option.

- H4: The vividness of video will lead to positive comparisons of the product that is actually consumed.

- H4a: Positive judgments of the food item will lead to positive evaluations of the video ad as a recommender.

We will conduct studies using a combination of methods such as laboratory experiments, a quasi-experimental design where we will manipulate digital signage content in a Café setting, and field studies. Eye-tracking will also be utilized.

\section{Conclusion}

In this poster, we have hypothesized that consumers will use video ads as reference heuristic or as a recommender for which food choices they should make under conditions of severe cognitive load or simply as novices entering a specific fast food outlet. Product venders and other industry representatives suggest that dynamic digital menu boards are effective at influencing consumer behavior. As a result, we believe that these technologies could be used to improve healthy eating if they were used to promote products with healthier attributes.

Although we have not yet collected data, our preliminary informal observations of peoples' buying behavior in relation to viewing menu board items suggest that these technologies do have the potential to influence decision makers. When we first encountered these technologies, our first reaction was that these technologies had great potential to "up sell" customers to higher margin products but we subsequently realized that these technologies could also be used to promote healthy eating. We are hopeful that the results of this research will demonstrate that dynamic digital menu boards do indeed have the potential to positively influence consumers' healthy eating behaviors and that venders will likewise adopt these technologies to promote healthy food alternatives.

\section{References}

1. Bettman, J., Luce, M., Payne, J.: Constructive Consumer Choice Processes. Journal of Consumer Research 25, 187-217 (1998)

2. Blackwell, R., Miniard, P., Engel, J.: Consumer Behavior, 9th edn. Harcourt, Inc., New York (2001)

3. Burke, R.: Behavioral effects of digital signage. Journal of Advertising Research 49(2), 180-186 (2009)

4. Engel, J., Blackwell, R., Kollat, D.: Consumer Behavior, 3rd edn., Hinsdale, Dryden (1978) 
5. Eppler, M., Mengis, J.: The Concept of Information Overload: A Review of Literature from Organization Science, Accounting, Marketing, MIS, and Related Disciplines. The Information Society, an International Journal 20(5), 1-20 (2004)

6. Hoyer, W.: An Examination of Consumer Decision Making for a Common Repeat Purchase Product. Journal of Consumer Research 11, 822-829 (1984)

7. Huang, E., Koster, A., Borchers, J.: Overcoming Assumptions and Uncovering Practices: When does the Public really look at Public Displays? In: Indulska, J., Patterson, D.J., Rodden, T., Ott, M. (eds.) PERVASIVE 2008. LNCS, vol. 5013, pp. 228-243. Springer, Heidelberg (2008)

8. Jacoby, J., Speller, D., Kohn, C.: Brand Choice Behavior as a Function of Information Load. Journal of Marketing Research 11, 63-69 (1974)

9. Muller, J., Wilmsmann, D., Exeler, J., Buzeck, M., Schmidt, A., Jay, T., Kruger, A.: Display Blindness: The Effect of Expectations on Attention towards Digital Signage. In: Tokuda, H., Beigl, M., Friday, A., Brush, A.J.B., Tobe, Y. (eds.) Pervasive 2009. LNCS, vol. 5538, pp. 1-8. Springer, Heidelberg (2009)

10. Nisbett, R., Ross, L.: Human Inference: Strategies and Shortcomings of Social Judgment. Prentice-Hall, New Jersey (1980)

11. Peters, A., Mennecke, B.: The Role of Dynamic Digital Menu Boards in Consumer Decision Making. In: CHI ACM Conference on Human Factors in Computing Extended Abstracts. ACM Press, New York (2011)

12. Taylor, S., Thompson, S.: Stalking the Elusive "Vividness" Effect. Psychological Review 89(2), 155-181 (1982)

13. The Buzz: Installation spotlight: POP appeal, http://svconline.com/ digitalsignage/features/digital_signage_wendys_0603/ 